\title{
Erratum to: Preserving the activity of enzymes under harsh oxidizing conditions: sol-gel entrapped alkaline phosphatase exposed to bromine
}

\section{ISGS Lifetime Achievement Award}

\author{
Hagit Frenkel-Mullerad • Racheli Ben-Knaz • \\ David Avnir
}

Published online: 23 April 2014

(C) Springer Science+Business Media New York 2014

\begin{abstract}
Chemically reactive sol-gel matrices hold the ability of protecting entrapped enzymes from destruction by external harsh chemicals. We show this concept by exposing alkaline phosphatase (AlP) to a strong oxidizing agent-bromine. In solution, AlP is immediately destroyed by this oxidant. When AlP was entrapped in hybrid silica sol-gel materials carrying double bonds, the reactivity of AlP was preserved after exposure to bromine under conditions which totally destroy it in solution. The matrices studied were vinylated and allylated silicas, and their protectability was compared to $n$-alkylated silicas and to silica itself. For instance, the reactivity of AlP entrapped in allylated silica after exposure to $25.6 \mathrm{mM}$ bromine solution is 40 times higher than its reactivity when entrapped in pure silica; and in solution the enzyme is totally destroyed at this concentration. Molecular level mechanisms for these observations are proposed.
\end{abstract}

Keywords Sol-gel · Sol-gel preserved enzymes · Oxidizing agent · Ormosil

The online version of the original article can be found under doi:10.1007/s10971-013-3226-z.

This article was submitted to be part of this special issue, but was previously published in Volume 69, Number 2 of the journal. It is reprinted here in its entirety.

H. Frenkel-Mullerad · R. Ben-Knaz · D. Avnir $(\bowtie)$ Institute of Chemistry and the Center for Nanoscience and Nanotechnology, Hebrew University of Jerusalem, 91904 Jerusalem, Israel

e-mail: david.avnir@mail.huji.ac.il

H. Frenkel-Mullerad

e-mail: hagitfm@gmail.com

\section{Background}

Alkaline phosphatase (AlP), like most other enzymes, is totally destructed when exposed to a strong oxidant such as bromine. Here we show how to protect an enzyme when exposed to such conditions. We do so by using the sol-gel materials methodology for enzyme entrapment [1]. Sol-gel entrapped enzymes [2-4] have already been shown to provide significant thermal stability [5-8], stability to extreme $\mathrm{pH}$ values [9-11], and stability to non-native environments [12-14]. In these earlier studies the protectability was attributed to the encaging itself [15]; here we extend these observations by showing protection against an oxidant due to active chemical scavenging of the destructive chemical by the matrix. Thus when the enzyme is entrapped within sol-gel derived olefinated silicas, and then exposed to bromine solution, the double bonds react with the bromine, and protect the enzyme. By comparing this mode of protection to entrapments in non-reactive matrices-sol-gel derived silicas and sol-gel-derived alkylated silicas-we were able to evaluate the weights of the bromine scavenging and of the physical entrapment to the protection of the enzyme; we find that this relative weight depends on the alkyl and alkenyl chain. Thus, the hybrid sol-gel material we used was based on vinyl $\left(\mathrm{CH}_{2}=\mathrm{CH}-\mathrm{Si}\right.$; VTS; here and below we use the name of the monomer as the name of the material), or allyl $\left(\mathrm{CH}_{2}=\mathrm{CH}-\right.$ $\mathrm{CH}_{2}-\mathrm{Si}$; ATS). In earlier studies we showed these olefinated sol-gel materials are highly reactive towards bromine, undergoing in water an hydrobromination reaction $[16,17]$ which proceeds according to Markovnikov's rule [18], as shown in Scheme 1, resulting in a bromohydrin and $\mathrm{HBr}$. The formation of an acid is an environmental change that the entrapped enzyme can withstand. We recall that we showed that sol-gel entrapped alkaline phosphatase 


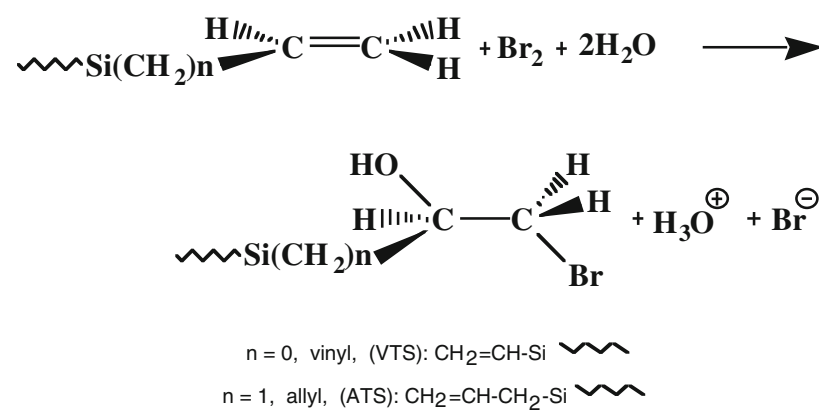

Scheme 1 The reaction of the olefin residues with bromine, under aqueous conditions

remains alive at $\mathrm{pH}$ values as low as $0.9(!)$ [16]. As mentioned above, in order to investigate the role of the double bonds of the alkenyl-Ormosils in the enzyme protection, two alkane-derived silica sol-gel materials were prepared where the chain length was kept, except that it was saturated, namely ethylated $\left(\mathrm{CH}_{3}-\mathrm{CH}_{2}-\mathrm{Si}\right.$, ETS $)$ and propylated $\left(\mathrm{CH}_{3}-\mathrm{CH}_{2}-\mathrm{CH}_{2}-\mathrm{Si}\right.$, PTS $)$ silicas. In order to investigate the role of the hydrophobicity of the chain, entrapment in pure TMOS-derived silica was carried out as well. On the practical level we recall that immobilized alkaline phosphatase is applied for monitoring both organophosphorus pesticides and heavy metal cations in analysis of environmental, biological, food samples, by measuring the inhibition effect on the enzymatic activity. Protection from oxidation by other chemicals that may be present in such samples is beneficial [19].

\section{Experimental details}

\subsection{Chemicals}

Tetramethoxysilane (TMOS), vinyltrimethoxysilane (VTS), allyltrimethoxysilane (ATS), ethyltrimethoxysilane (ETS), propyltrimethoxysilane (PTS) alkaline phosphatase (AlP, cat. no. P-3681), p-nitrophenyl phosphate (pNPP), were all obtained from Sigma-Aldrich. Bromine $99.5 \mathrm{wt} \%$ was obtained from Merck. Glycine- $\mathrm{NaOH}$ buffer solution $0.05 \mathrm{M}\left(1 \mathrm{mM} \mathrm{MgCl}_{2}\right)$ was prepared by dissolving glycine and $\mathrm{MgCl}_{2}$ (from $\mathrm{BDH}$ ) in distilled water and adjusting the $\mathrm{pH}$ with $1.0 \mathrm{M} \mathrm{NaOH}$ to 9.5 .

\subsection{Enzyme entrapment procedures}

The matrices were prepared via the "two-step" method [20] from a mixture of the alkenyltrimethoxy silane (RTS) and TMOS with a molar ratio of RTS:TMOS $=1: 2$, by the following procedure: a mixture of 0.9 mol RTS (VTS:
$0.140 \mathrm{ml}$; PTS: $0.160 \mathrm{ml}$; BTS: $0.145 \mathrm{ml}$; ATS: $0.150 \mathrm{ml}$ ), $0.265 \mathrm{ml}$ TMOS $(1.8 \mathrm{~mol})$ and $0.491 \mathrm{ml} \mathrm{HCl}(2.5 \mathrm{mM})$ was mixed for $30 \mathrm{~min}$ at $30{ }^{\circ} \mathrm{C}$. For obtaining a pure silica matrix $0.400 \mathrm{ml}$ TMOS $(2.7 \mathrm{~mol})$ was used instead of the silane mixture mentioned above. The resulting sol was cooled for $30 \mathrm{~min}$ to $4{ }^{\circ} \mathrm{C}$. $0.930 \mathrm{ml}$ enzyme solution $(7.4 \mathrm{U} / \mathrm{ml}$ in glycine- $\mathrm{NaOH}$ buffer $\mathrm{pH} 9.5)$ was then transferred to the ice-cooled sol solution and mixed briefly. From this mixture, $0.05 \mathrm{ml}$ was transferred to polystyrene cuvettes and left to gel. $10 \mathrm{~min}$ after gelation the gels were covered with $0.25 \mathrm{ml}$ of a glycine- $\mathrm{NaOH}$ buffer solution ( $\mathrm{pH}$ 9.5), sealed with Parafilm and left to age at $4{ }^{\circ} \mathrm{C}$ for $24 \mathrm{~h}$. One day after preparation, $0.05 \mathrm{ml}$ of the supernatant buffer solution was transferred to cuvettes in order to determine the amount that was not entrapped (by checking the enzymatic activity of this solution, as described below). Residual un-entrapped enzyme was then removed by replacing the remaining buffer solution with $0.25 \mathrm{ml}$ of fresh buffer and incubating again at $30{ }^{\circ} \mathrm{C}$ for $30 \mathrm{~min}$. This rinse was also tested for enzymatic activity. The third rinse was found to be enzyme free, and these sol-gel materials were used for the further study. We refer to enzyme concentration within the gels as the amount used for entrapment minus the various washings. It should be noted that the amount of entrapped enzyme differs in the matrixes: of the initial amount added to entrapping mixture, the alkenyl matrices and silica itself entrapped practically all, while the entrapping capacity of the alkylated silica half/two thirds of the maximal value. Therefore the activity is reported in terms of the normalized (T.O.N.) values. Finally, other ratios of monomers were tested, and the selected one, which is reported here, was chosen because of the minimal leaching of enzyme from it.

\subsection{Exposure of the entrapped enzyme to bromine} and determination of its activity

Following the matrix rinse as described above, $0.250 \mathrm{ml}$ of bromine solution (3.95-25.6 $\mathrm{mM}$ in water) was added to the gels. The cuvettes were sealed and left for $5 \mathrm{~min}$ followed by replacing the unreacted bromine solution with $0.25 \mathrm{ml}$ of $2.7 \mathrm{mM}$ of the substrate (pNPP) in the glycine$\mathrm{NaOH}$ solution ( $\mathrm{pH}$ 9.5). We recall that AlP catalyses the hydrolysis of phosphoesters- $p$-nitrophenyl phosphate (pNPP) in our case- to phosphate and to the corresponding alcohol or phenolate- $p$-nitrophenol $(\mathrm{pNP})$ in our case [21]:

$\mathrm{R}-\mathrm{O}-\mathrm{PO}_{3}^{2-}+\mathrm{H}_{2} \mathrm{O} \stackrel{\text { AIP }}{\longrightarrow} \mathrm{R}-\mathrm{OH}+\mathrm{HPO}_{4}^{2-}$

The initial rate of the reaction, taken as the initial slope of the kinetics graph. In cases were a lag appeared due to diffusion limitations the slope was calculated from the end 


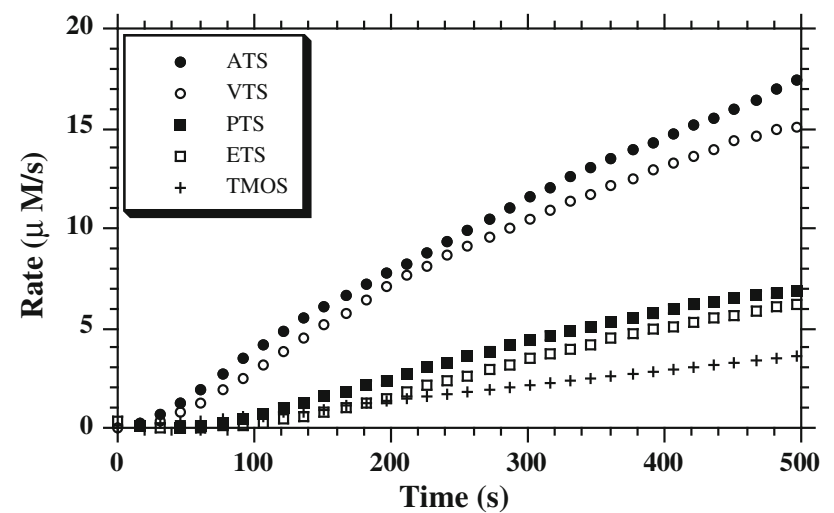

Fig. 1 The kinetics of alkaline phosphatase entrapped inside the different matrix after exposure to $13.3 \mathrm{mM}$ bromine aqueous solution

of that lag. The reaction progress was determined by following the formation of pNP through its absorption maximum at $405 \mathrm{~nm}$ (using HP-8453 spectrophotometer). The apparent turn-over-numbers (T.O.N.) were calculated by dividing the rate of reaction by the concentration of the entrapped enzyme. The reported results are the mean of 3 experiments. For comparison to solution, the reaction was carried out in glycine-NaOH buffer. For this, $0.050 \mathrm{ml}$ of the enzyme solution was transferred to a cuvette with $0.250 \mathrm{ml}$ bromine solution. After $5 \mathrm{~min} 0.250 \mathrm{ml}$ of the substrate were added and the formation of the pNP was followed as described above. Additional blank tests were carried out in TMOS, in ATS and in solution, as described above but without the bromine; here, the T.O.N.'s were 27.5 and $15.0 \mathrm{~s}^{-1}$, respectively.

\section{Results and discussion}

Figure 1 presents the activity of the entrapped enzyme in the different matrixes after $5 \mathrm{~min}$ exposure to $13.3 \mathrm{mM}$ bromine solution. The results clearly show the enzyme protectability of the olefinated matrices (AlP@ATS and AlP@VTS), the much lower protectability of the alkylated matrices (AlP@PTS and AlP@ETS), which are still better than the protectability of pure TMOS-derived silica. Similar measurements were taken with other bromine concentrations ( $25.6 \mathrm{mM}$ and $3.95 \mathrm{mM}$-see below).

The left parts of Fig. 2 presents blank measurements in solution or with TMOS-derived silica, needed to appreciate the results shown in that figure for the hybrid silicas. In solution exposure of AlP resulted in total destruction for the two higher bromine concentrations; barely detected activity is observed only at the lowest bromine concentration of $3.95 \mathrm{mM}$. When pure silica is used (Fig. 2, second from left) some protectability is seen, and it follows the reverse order of the concentration of bromine. The protectability in this case reflects the shielding of the

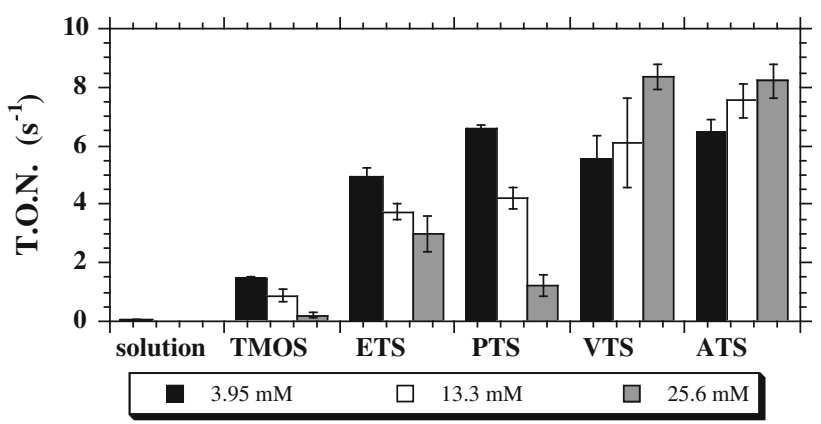

Fig. 2 The activity of the enzyme AlP entrapped in the different matrixes studied in this report, after exposure to three different bromine concentrations

protein from being oxidized at various locations of its outer regions, and the fact that pNPP does compete with bromine on diffusional pathways to the active site. Of course, as the bromine concentration increases, the competition from it becomes more efficient. The center portion of Fig. 2 shows the results for the alkylated AIP@ETS and AlP@PTS, namely, how much protectability is there due to the hydrophobization of the matrix, without the reactive residues. It is seen that the longer propyl chain better protects than the ethyl chain, and this reflects the difficulty in the penetrability of the aqueous solution of bromine. Interestingly, the hydrophobization affects less the substrate- $\mathrm{pNPP}-$ than the bromine and this is due to the fact that the molecule has a large hydrophobic moiety, unlike the hydrophilic water solvated bromine (and its hydrophilic hydrolysis equilibrium products, $\mathrm{H}^{+}+\mathrm{Br}^{-}+\mathrm{HOBr}$ ). The relation between protectabilty and concentration is as in pure silica, namely, the higher the concentration of bromine the more of the enzyme is destroyed, but to a much lesser degree. We emphasize it, because when it comes to the olefinated silicas, quite unexpectedly this trend is reversed (right side of Fig. 2) - the best activity is with the highest bromine concentration. We shall comment on it shortly, but first we note that indeed, the best protection is provided by the vinylated and allylated silicas, that is, in addition to the hydrophobic effect we have here the silica acting as an active sponge, trapping and converting the bromine into hydrobromine residues which remain covalently attached.

However, unlike the simple alkyls (and pure silica) we see here also an increase in activity with bromine, at the range of concentration studied. For understanding this phenomenon we shift our focus from bromine to the substrate, pNPP and to the product pNP: Note that the hydrophilic double bonds are converted to $\mathrm{C}-\mathrm{OH}$, that is, these chains gain some hydrophilicity, and the more of it with the higher bromine concentrations. This amphiphilic nature which develops is quite supportive of diffusion of pNPP, itself an amphiphilic molecule. In this hydrophobic/ 
hydrophilic balance pNPP gains and bromine loses. It is obvious that this behavior has its limits at very high bromine concentrations, but such extreme conditions were not searched for, as comparison was made with bromine concentrations, which destroy the enzyme totally in solution. Finally we note that the reaction between the olefin and the bromine solution yields the by-product, hydrobromic acid, which lowers the $\mathrm{pH}$ [22], and we already described protection against $\mathrm{pH}$ changes elsewhere [16].

To summarize these observations with some numbers, note, for example, that the reactivity of AlP@ATS after exposure to $25.6 \mathrm{mM}$ bromine solution is 40 times higher than its reactivity in TMOS-derived silica after exposure to the same bromine solution, and that in solution only, the enzyme is totally destructed. The serendipitous finding of this study, namely that a destructive agent improves the activity of the enzyme-protective matrix, suggests a new interesting perspective in designing enzyme carriers, addressing the challenge of enzymatic systems that combine satiability, protection and improvement of reactivity.

Acknowledgments Supported by the Ministry of Science, the Eshkol Scholarship (to H. F.-M.), the Infrastructure Project (Tashtiot), and the French-Israeli AFIRST Program.

\section{References}

1. Braun S, Rappoport S, Zusman R et al (1990) Biochemically active sol-gel glasses: the trapping of enzymes. Mater Lett 10:1-5

2. Avnir D, Braun S, Lev O, Ottolenghit M (1994) Enzymes and other proteins entrapped in sol-gel materials. Chem Mater 6:1605-1614

3. Avnir D, Coradin T, Lev O, Livage J (2006) Recent bio-applications of sol-gel materials. J Mater Chem 16:1013

4. Jin W, Brennan JD (2002) Properties and applications of proteins encapsulated within sol-gel derived materials. Anal Chim Acta 461:1-36

5. Nguyen DT, Smit M, Dunn B, Zink JI (2002) Stabilization of creatine kinase encapsulated in silicate sol-gel materials and unusual temperature effects on its activity. Chem Mater 14:4300-4306

6. Yu J, Ju H (2002) Preparation of porous titania sol-gel matrix for immobilization of horseradish peroxidase by a vapor deposition method. Anal Chem 74:3579-3583
7. Besanger TR, Chen Y, Deisingh AK et al (2003) Screening of inhibitors using enzymes entrapped in sol-gel-derived materials. Anal Chem 75:2382-2391

8. Rutenberg A, Vinogradov VV, Avnir D (2013) Synthesis and enhanced thermal stability of albumins@alumina: towards injectable sol-gel materials. Chem Commun (Camb) 49:5636-5638

9. Flora KK, Brennan JD (2001) Effect of matrix aging on the behavior of human serum albumin entrapped in a tetraethyl orthosilicate-derived glass. Chem Mater 13:4170-4179

10. Chen Q, Kenausis GL, Heller A, et al (1998) Stability of oxidases immobilized in silica gels. 7863:4582-4585

11. Zheng L, Flora K, Brennan JD, Protein SGM (1998) Improving the performance of a sol-gel-entrapped metal-binding protein by maximizing protein thermal stability before entrapment. Chem Mater 10:3974-3983

12. Takahashi H, Li B, Sasaki T, et al (2000) Catalytic activity in organic solvents and stability of immobilized enzymes depend on the pore size and surface characteristics of mesoporous silica. Chem Mater 12:3301-3305

13. Van Unen DJ, Engbersen JF, Reinhoudt DN (2001) Sol-gel immobilization of serine proteases for application in organic solvents. Biotechnol Bioeng 75:154-158

14. Wang P, Dai S, Waezsada SD et al (2001) Enzyme stabilization by covalent binding in nanoporous sol-gel glass for nonaqueous biocatalysis. Biotechnol Bioeng 74:249-255

15. Lloyd C, Eyring E (2000) Protecting heme enzyme peroxidase activity from $\mathrm{H}_{2} \mathrm{O}_{2}$ inactivation by sol-gel encapsulation. Langmuir 16:9092-9094

16. Frenkel-Mullerad H, Avnir D (2005) Sol-gel materials as efficient enzyme protectors: preserving the activity of phosphatases under extreme ph conditions. J Am Chem Soc 127:8077-8081

17. Elimelch H, Avnir D (2012) Chemical reactivity of hybrid particles. RSC Adv 2:863

18. Boguslavskaya LS (1972) Preparation of vicinal difunctional compounds by the converted electrophilic halogenation of multiple bonds. Russ Chem Rev 41:740-749

19. García Sánchez F, Navas Díaz A, Ramos Peinado M, Belledone C (2003) Free and sol-gel immobilized alkaline phosphatasebased biosensor for the determination of pesticides and inorganic compounds. Anal Chim Acta 484:45-51

20. Brinker C, Keefer K (1982) Sol-gel transition in simple silicates. J Non Cryst 48:47-64

21. McComb RB Jr, Bowers GN, Posen S (1979) Alkaline phosphatase. Springer, Berlin

22. Frenkel-mullerad H, Avnir D (2000) The chemical reactivity of sol-gel materials: hydrobromination of ormosils. Chem Mater 12:3754-3759 